\title{
UNA NUEVA EMISIÓN DE LA CECA DE ERKAUIKA
}

PERE PAU RIPOLLÈS ALEGRE ${ }^{1}$

(1) Grup d'Investigació GRAM. Dpt. Prehistòria, Arqueologia i Història Antiga. Universitat de València. Pere.P.Ripolles@uv.es

La ceca que acuñó monedas con la leyenda ERKAUIKA pudo estar localizada en La Muela (Alcocer, Guadalajara), en las proximidades de donde se fundó posteriormente el municipio de Ercavica, aunque no existe una certeza absoluta al respecto (Fuentes 1993; 173-174; Lorrio 2001: 127-133 y 2012: 272-278; un resumen de las diferentes opciones propuestas en Espinosa 2013, 73-75).

A esta ceca se le atribuyen dos emisiones monetarias, que se diferencian por los anversos. La que se supone más antigua (ACIP 1854; Gomis 1995, emisión I) muestra un retrato a derecha, delante un delfín y los signos

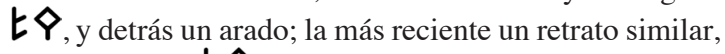
con los signos $€ ४$ delante y arado detrás (ACIP 1855; Gomis 1995: emisión II). Los reversos son similares, un jinete con lanza a derecha; debajo la leyenda $\llcorner ९ \wedge \uparrow \boldsymbol{N} \wedge$, sobre línea en la primera emisión y

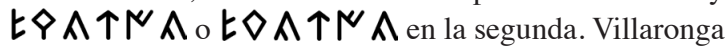
registra bajo sus entradas $C N H$ 288/3 y ACIP 1856, un semis que no describe ni ilustra. La nota que acompaña a dicho tipo indica haberla visto en la Asociación Numismática de Zaragoza, en el año 1988; sin embargo, nunca se ha publicado una imagen de la misma.
Ambas emisiones acuñaron una reducida cantidad de monedas, pues Gomis (1995: 16) sólo identifica un cuño de anverso y tres de reverso para la primera y tres de anverso y dos de reverso para la segunda. Con este número de cuños de anverso la producción tuvo que ser necesariamente escasa, como lo sugiere el reducido número de monedas documentadas y la extrema rareza de sus hallazgos ${ }^{1}$.

Por lo que respecta a la cronología de su emisión, Villaronga en $C N H$ p. 287 y $A C I P$ p. 359 , fecha la primera a principios de la segunda mitad del s. II a.C. y la segunda en el último tercio del s. II a.C. La misma cronología mantuvo Gomis (1995: 18), y así ha continuado hasta ahora, ya que de acuerdo con las evidencias disponibles parece una opción razonable. El estilo de los retratos apoya esta cronología, ya que los de la primera emisión tienen similitudes estilísticas con algunos retratos de la fase final de la emisión de Bilbilis con símbolo signo $M$; mientras que los de la segunda se asemejan bastante a algunas unidades de Bentian (ACIP 1673 y 1678).

En los últimos años se han publicado tres piezas que definen una tercera emisión, que presumiblemente hay que situar detrás de las dos ya conocidas. La dificultad de lectura de la leyenda de reverso y el desgaste o mala 
conservación de las monedas han sido los motivos de que no hubiera sido identificada, pues uno de los ejemplares se conocía desde hacía tiempo.

La primera pieza fue publicada en el catalogo de subasta Áureo 2/7/2003, lote 106, y fue adquirida por G. Cores (Madrid). Áureo la atribuyó correctamente a Erkauika, pues la leyenda, aunque tiene los dos primeros signos poco marcados, permitía una identificación segura. El anverso muestra los diseños con bastante relieve; en el catálogo de subasta se describió como cabeza imberbe, detrás $X$ y delante dos arados contrapuestos. Por lo que respecta al reverso, identificaron un jinete lancero y la leyenda $₹ \mathcal{P} A \uparrow N A$, bajo línea. Las diferencias con respecto a los dos tipos conocidos hasta el momento les llevaron a calificarla, correctamente, como inédita, aunque la descripción debe modificarse en algunos detalles, a la vista de las nuevas piezas conocidas. A pesar de que las subastas de Áureo son ampliamente conocidas, la existencia de esta moneda pasó desapercibida o no tuvo ningún eco en la investigación, dado que Villaronga no la recogió en el corpus $A C I P$.

En el año 2009, en una búsqueda de piezas ibéricas recogimos de la web OMNI 9/10/2009 una moneda singular que tampoco pertenecía a los dos tipos conocidos. Comparamos la nueva moneda con la que subastó Áureo y todo parecía indicar que se trataba del mismo tipo y que estaban fabricadas con los mismos cuños. Tras un examen minucioso de las imágenes, para descartar la posibilidad de una fabricación reciente, todo parecía indicar que se trataba de piezas genuinas, aunque la excelente conservación de la moneda del Foro OMNI, suscitaba algunas dudas.

Su existencia quedó confirmada, en 2013, cuando se desveló la existencia de un tercer ejemplar como consecuencia de la venta de las monedas de la colección de la HSA de Nueva York. Esta moneda estaba depositada en la ANS de Nueva York, integrante de la colección de la HSA ( $\left.n^{\circ} 11602\right)$, pero no había sido identificada y estaba en la bandeja de cecas inciertas de Hispania. Su impronta aparece en el Album de improntas de las monedas de la colección Cervera (1895: folio 97), confeccionado por Vives, y en él se anotó, debajo de la moneda, la leyenda tamaniu (en ibérico) con interrogación; obstante, la pieza se encuentra dentro de un grupo de monedas catalogadas como inciertas. Fue subastada por Vico el 28/02/2013, lote 132 , cuyo catálogo la describió como perteneciente a ceca indeterminada. La leyenda de reverso no tiene una fácil lectura, de los tres signos que se atrevieron a leer [...]LUN[...]. dos lo fueron de forma incorrecta; sin embargo la descripción de las figuras fue correcta, aunque algunos símbolos pueden ser identificados de otro modo.

En cuanto a los tipos de esta nueva emisión, los símbolos y la posición de la leyenda de reverso se disponen de forma diferente a las dos emisiones ya conocidas. $\mathrm{Su}$ descripción sería:

Anv. Cabeza masculina, a dcha.; delante, dos delfines o un delfín en la parte superior y un arado en la inferior; detrás, X.

Rev. Jinete con lanza, a dcha.; encima, $X$; debajo, en el exergo, leyenda ibérica $F \Phi A \uparrow N A$.

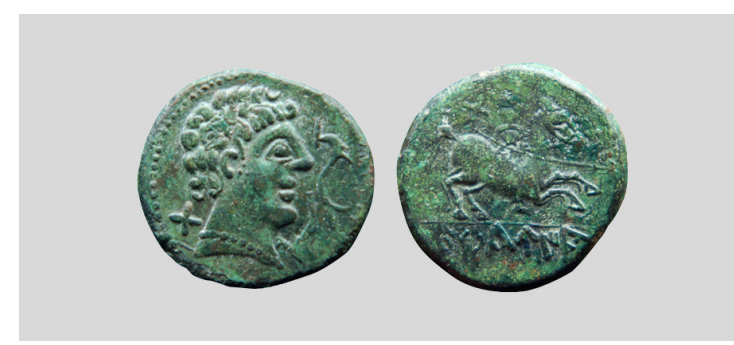

A: Web Foro OMNI 9/10/2009.

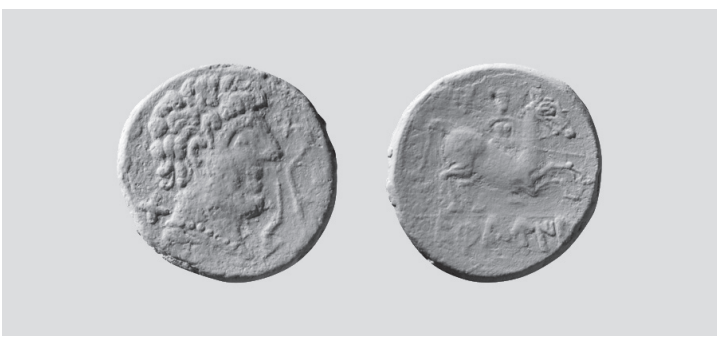

B: Madrid. Col. G. Cores, 10,20 g, 1h (=Áureo 2/7/2003, lote 106).

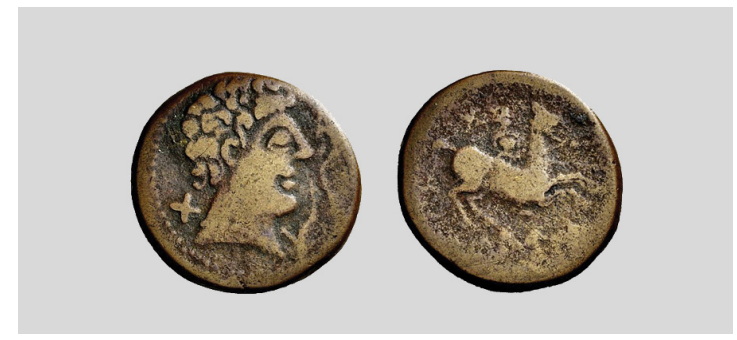

C: Madrid. col. G. Cores, 10,40 g, 10 h (=Vico 28/02/2013, lote 132, ex HSA 11602). 
Dos observaciones debemos hacer sobre la descripción que proponemos. La primera se refiere a la identificación del símbolo que aparece delante de la cara, en su parte inferior. No estamos seguros de que deba identificarse como un delfín, pues podría tratarse de un arado mal grabado; es decir, podría ser una esquematización de los arados que aparecen en las dos emisiones anteriores, los cuales ya son bastante esquemáticos. Tampoco estamos seguros de que el símbolo que aparece en el reverso, sobre el jinete, sea un aspa, ya que la mala conservación de las monedas no permite ser concluyente en este tema; sin embargo, el hecho de que en anverso sea claramente un aspa, podría favorecer la opción de que se reprodujese idéntico motivo en reverso.

Las piezas no destacan por una excelente factura. El anverso está bien ejecutado, con volúmenes redondeados y prominentes. El cabello está trazado a base de arcos con algún rizo de gancho. Los ojos son redondos y saltones. No hemos encontrado paralelos próximos, pero da la impresión que nos encontramos frente a una producción del s. I a.C. El reverso, en cambio, está peor ejecutado, especialmente en lo que concierne a la cabeza del caballo y al cuerpo del jinete. El trazo de la leyenda es también más irregular que en las dos emisiones anteriores; la leyenda presenta una variante epigráfica en el trazado de los signos $\boldsymbol{e}$ y $\boldsymbol{k} \boldsymbol{a}$, siendo otro detalle más que la diferencia. En la primera emisión el signo $\boldsymbol{k} \boldsymbol{a}$ se grabó en la forma $\lambda$, en la segunda con la forma $\widehat{\Lambda}$ y en la tercera $\hat{\lambda}$. El signo $\boldsymbol{e}$ se grabó en las emisiones ya conocidas con la forma $k$, pero en la nueva emisión los trazos oblicuos se orientan hacia abajo, F. No cabe duda que se trata de una nueva emisión, ya que las diferencias con las anteriores son significativas.

Las tres monedas conocidas se acuñaron con la misma pareja de cuños, por lo que sólo existen, de momento dos cuños, uno de anverso y otro de reverso. Eso quiere decir que presumiblemente sólo se acuñaron entre 10.000 y 20.000 monedas, de acuerdo con las estimaciones aceptadas de producción de cuños.

El escaso número de monedas conocido, para las que ni tan siquiera tenemos el peso de todas, no permite ser concluyente en cuanto a su metrología, pero el hecho de que los pesos de dos de ellas sean bastante coincidentes, sugiere que el peso medio resultante, $10,30 \mathrm{~g}$, puede tomarse como indicativo. Con este peso, la tercera emisión se puede relacionar con el peso medio de la segunda, que es de poco más de $10 \mathrm{~g}$. Villaronga, en $C N H$ y $A C I P$, ofrece $10,39 \mathrm{~g}$, a partir de
18 ejemplares; Gomis (1995: 19) da una media de 9,97 g, con 17 ejemplares y nuestros cálculos, a partir de 19 piezas, 10,03 g.

El último aspecto que queda por considerar es el de la cronología. Esta emisión presenta los mismos problemas que las anteriores. No hay hallazgos que contribuyan a fecharlas. La única vía de aproximación continúa siendo la tipológica y metrológica. El peso medio es similar a la emisión II y el estilo parece un poco más avanzado, aunque esto no presupone nada. La leyenda en signario ibérico da a entender que se acuñó en una fecha anterior a ca. 50/45 a.C., momento en el que la escritura ibérica deja de utilizarse en las cecas de la Citerior. Por otra parte, el patrón de $c a$. 10 g es compatible con una cronología del s. I a.C.

En consecuencia, la nueva emisión podría considerarse como la última de la ciudad celtibérica. Esta tercera serie quedaría enmarcada dentro del primer tercio del s. I a.C. si la fecha propuesta por Villaronga (ACIP p. 359) de último tercio del s. II a.C. para la segunda emisión fuera correcta y si también lo fuera la fecha de destrucción o abandono durante las Guerras Sertorianas del yacimiento La Muela, en el que se supone asentada esta ciudad (Lorrio 2001: 130 y 2012: 276; Espinosa 2013: 83-86).

\section{BIBLIOGRAFÍA}

ACIP = VILLARONGA, L.; BENAGES, J. (2011): Ancient Coinage of the Iberian peninsula. Greek / Punic / Iberian / Roman, Barcelona.

CNH = VILLARONGA, L. (1994): Corpus Nummum Hispaniae ante Augusti Aetatem, Madrid.

ESPINOSA, D. (2013): Ercávica, [oppidum] Latinorum veterum. Romanización e integración jurídica en la provincia de Guadalajara a través del derecho latino, La romanización en Guadalajara . Arqueología e historia (M. L. Cerdeño, E. Gamo y T. Sagardoy, coord.), Madrid, 73-89.

FUENTES, A. (1993): Las ciudades romanas de la Meseta Sur, Catálogo General de la Ciudad Hispanorromana, Madrid, 159-189.

GOMIS, M. (1995): Erkauika: las acuñaciones ibéricas, Numisma 236, 9-28.

LORRIO, A. J. (2001): Ercavica. La muralla y topografía de la ciudad, Madrid, 2001.

LORRIO, A. J. (2012): Procesos de continuidad y discontinuidad entre los oppida celtibéricos y las ciudades romanas de la Meseta Sur: los casos de Segobriga y Ercavica, La ciudad romana en Castilla-La Mancha, Cuenca, 225-285. 
OCHARÁN, J. A. (2002): Monedas perdidas en un combate inédito de las guerras cántabras en el valle de Cuartango (Álava). Monedas partidas, monedas forradas, X Congreso Nacional de Numismática. Actas, Madrid, 335-341.

RUBIO, R. (2013): Los orígenes de Ercávica y su municipalización en el contexto de la romanización de la Celtiberia meridional, Vínculos de Historia 2, 169-183.
UNZUETA, M. OCHARÁN, J. A. (2006): IX. El campo de batalla de Andagoste (Álava), Los campamentos romanos en Hispania (27 a.c.-192 d.c.), Gladius, anejos 9, 473-492.

VALERO, M. Á. (2013): El cambio de patrón poblacional en el territorium de Ercávica: avance sobre un proyecto de evolución del paisaje en La Alcarria, La romanización en Guadalajara. Arqueología e historia (M. L. Cerdeño, E. Gamo, y T. Sagardoy, coords.), Madrid, 211-236. 